\title{
The temporal dynamics of consolidation and reconsolidation decrease during postnatal development
}

\author{
Solène Languille, Nadège Gruest, Paulette Richer, and Bernard Hars ${ }^{1}$ \\ Université Paris-sud, Laboratoire de Neurobiologie de l'Apprentissage, de la Mémoire et de la Communication, UMR 8620, CNRS, \\ 91405 Orsay. France
}

\begin{abstract}
The temporal dynamics of consolidation and reconsolidation of taste/odor aversion memory are evaluated during rat pup growth at postnatal days 3,10, and 18. This is assessed through the temporal gradients of efficacy of a protein synthesis inhibitor (anisomycin) in inducing amnesia after either acquisition (consolidation) or reactivation (reconsolidation). The results show a progressive reduction with age of the delay during which the inhibitor is able to induce amnesia. Control experiments rule out a reduction of anisomycin efficacy due to blood brain barrier growth or decrease in protein synthesis inhibition. Thus, these results present the first evidence that the protein synthesis-dependent phase of memory stabilization requires less time with age. This decrease occurs in parallel for consolidation and reconsolidation. Such changes in the dynamics of memory processing could contribute to the cognitive improvement associated with development.
\end{abstract}

Neurobiological changes occurring during development have been extensively explored, but the functional consequences of these changes for cognition are still not well understood. Research on cognitive development has demonstrated very early learning capacities in vertebrates; different kinds of associative learning may be acquired by neonates and even by the fetus (Smotherman et al. 1982; Kehoe and Blass 1986; Cheslock et al. 2000; Sullivan 2001; Smotherman 2002; Gruest et al. 2004a; Shionoya et al. 2006). Some of these early acquisitions have been shown to be retained in the long term, but the characteristics of long-term memory in the course of development are still poorly known, particularly concerning its stabilization.

In the adult, it is well known that memory stabilization is not instantaneous but requires time for the biological processes involved. To be stored in the long term, the memory trace must be consolidated (McGaugh 1966, 2000) and this consolidation requires new protein synthesis (Davis and Squire 1984). Thus, protein synthesis inhibitors given at the time of acquisition, or just afterward, cause amnesia by blocking consolidation. Recently, numerous experiments have enriched this notion by showing that retrieval of a previously consolidated memory induces a new period of lability and that stabilization of the memory in the long term requires a new wave of protein synthesis (for reviews, see Nader 2003; Dudai and Eisenberg 2004; Alberini 2005; Sara and Hars 2006), demonstrating the so-called reconsolidation phenomenon (Nader et al. 2000; Sara 2000).

Despite the theoretical importance of consolidation and reconsolidation, little is known about the emergence of these characteristics of memory during development. We have recently shown that consolidation and reconsolidation can be detected in the neonate and so may be considered as innate properties of memory processing (Gruest et al. 2004b). However, that does not rule out any possibilities of ontogenetic modifications of these memory characteristics. An indication of this possibility is that retrograde amnesia may be induced in the pup one hour after conditioned aversion training, a delay which has never been ob-

\footnotetext{
${ }^{1}$ Corresponding author.
}

E-mail bernard.hars@u-psud.fr; fax 33-1-69-15-77-26.

Article is online at http://www.learnmem.org/cgi/doi/10.1101//m.933208. served in the adult in the same kind of learning. Thus, the present experiments are aimed at testing the hypothesis that the temporal dynamics of consolidation and reconsolidation may change during postnatal development.

To address this question, conditioned taste/odor aversion is a convenient paradigm as this basic learning may be acquired by the pup (Gruest et al. 2004b) and followed until adulthood. Using this paradigm (Garcia et al. 1966), the pup receives aromatized milk (conditioned stimulus [CS]) in a suckling session, followed by $\mathrm{LiCl}$ injection inducing a malaise (unconditioned stimulus [US]). The pup associates milk and malaise, thereby, refusing the nipple with aromatized milk when presented later. To assess the requirement of de novo protein synthesis for memorization of this learning, we gave the protein synthesis inhibitor anisomycin (AN) after either acquisition (consolidation) or reactivation (reconsolidation). To detect a modification with age of this requirement for new protein synthesis, the amnesic effect of AN in both conditions was evaluated in the infant rat at different stages of the pre-weaning period: postnatal days 3 (P3), 10 (P10), and 18 (P18).

\section{Results}

\section{Post-trial effect of anisomycin when given at different ages}

We first tested whether protein synthesis was required for aversion memory consolidation and reconsolidation at different preweaning ages. Protein synthesis was blocked by injecting AN immediately after either training or retrieval. This treatment was applied to pups that were conditioned at P3, P10, or P18.

\section{Consolidation}

At each age, rat pups were subjected to two conditions: either conditioned (CS-US) or nonconditioned (CS---US); for the latter, the CS and US were separated by a long delay. In each condition, one group received AN and the other saline i.p. immediately after the US.

A two-way ANOVA (condition $\times$ drug) revealed a significant interaction at P3 $\left(F_{(1,38)}=12.65 ; P=0.001\right)$, at P10 
$\left(F_{(1,23)}=44.24 ; P<0.0001\right)$, and at P18 $\left(F_{(1,45)}=11.78 ; P=0.001\right)$ with a main effect of condition and drug, indicating a differential effect of AN on paired and nonpaired groups (see Fig. 1A).

At P3, P10, and P18 the pups of the paired CS-US group expressed a clear aversion when compared with those of the nonpaired CS---US group $(P<0.0001$ in each case), thus the conditioning was effective at the three ages.

AN had no nonspecific effect on retention performance; the two nonconditioned groups, with or without $\mathrm{AN}$, were not different at any age.
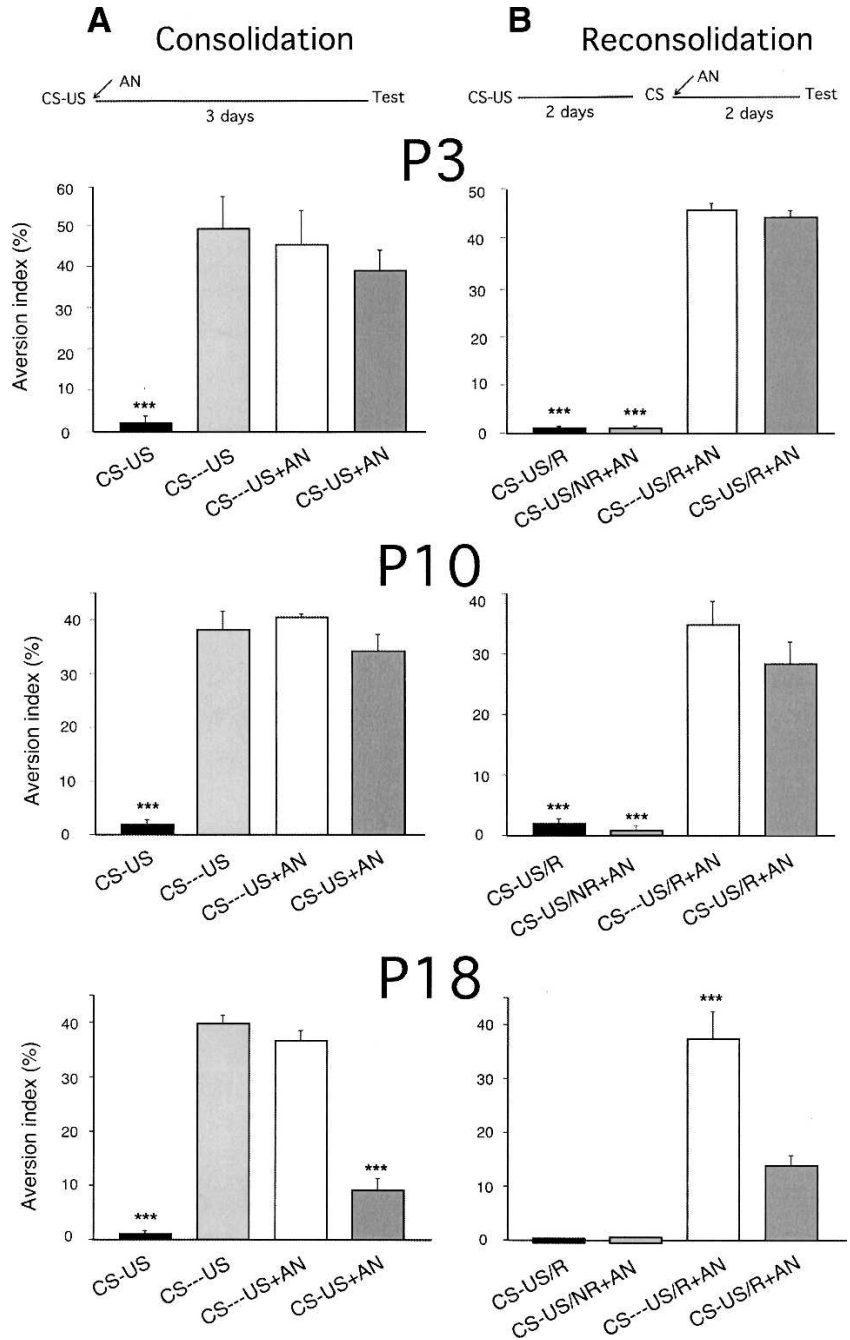

Figure 1. Effect of anisomycin (AN) at a dose of $42 \mathrm{mg} / \mathrm{kg}$, given immediately after training $(A)$ or after reactivation $(B)$ in rat pups. Training was at different ages after birth: P3, P10, or P18. The lower the index, the more the aversion. (A) Pups of group CS-US $(n=11,7,13)$ received aromatized milk paired with $\mathrm{LiCl}$ and those of CS-US+AN $(n=10,7,12)$ received AN i.p. immediately after pairing. Two control groups were submitted to an unpaired condition ( $\sim 8 \mathrm{~h}$ between CS and US), either followed by saline (CS---US, $n=12,6,12)$ or by AN injection (CS--US+AN, $n=9,7,12$ ). Retention test took place $3 \mathrm{~d}$ after training. (B) Two groups were paired and reactivated either without (CS-US/R, $n=11,8,8$ ) or with AN treatment (CS-US/R+AN, $n=12,8,9)$. A control group was unpaired, cued, and received AN (CS---US/R+AN, $n=12,7,9)$, and another one was paired but was not reactivated before AN (CS-US/NR+AN, $n=12,9,9$ ). Reactivation took place $2 \mathrm{~d}$ after training and retention test $2 \mathrm{~d}$ later. Error bars indicate SE. ${ }^{* * *} P<0.001$. When learning was either on $\mathrm{P} 3$ or $\mathrm{P} 10$, anisomycin abolishes conditioned aversion after both training and reactivation. On P18 pups, anisomycin has only a partial amnesic effect in both conditions.
AN abolished the conditioned aversion at P3 and P10; at these ages the aversion behavior of the conditioned pups receiving AN was not significantly different from those of the nonconditioned ones $(P>0.05)$ but was different from those of the conditioned non-AN-treated ones $(P<0.001)$. At P18 the amnesia was weaker; the conditioned AN-treated pups expressed an intermediary aversion between conditioned non-AN-treated ones and nonconditioned ones; these pups were different from those of the three other groups $(P<0.001$ in each case).

\section{Reconsolidation}

In these experiments we also used four groups: Two groups were conditioned and cued (CS alone) 2 d later, one without AN (CS$\mathrm{US} / \mathrm{R}$ ) and the other receiving AN just after the cue (CS-US/ $\mathrm{R}+\mathrm{AN}$ ), and two groups were nonconditioned, one receiving AN after the cue (CS---US/R+AN) and the other one was not cued but received $\mathrm{AN}$ at the same moment (CS---US/NR+AN). One-way ANOVA revealed an effect of group at the three ages $\left(F_{(3,43)}=567\right.$; $P<0.0001, F_{(3,28)}=45.38 ; P<0.0001$, and $F_{(3,31)}=39.53$; $P<0.0001$, respectively) (see Fig. 1B).

The cueing episode did not alter aversion memory; the aversion was expressed in the conditioned and cued non-AN-treated pups when compared to the nonconditioned ones at the three ages $(P<0.0001$ in each case) .

AN never had an amnesic effect when it was not contingent to the cue; at every age the conditioned noncued pups receiving AN expressed aversion similar to that of the conditioned nonAN-treated ones $(P>0.05$ in each case).

AN after cueing had a full amnesic effect on P3 and P10 pups; the conditioned pups receiving AN post-cueing did not differ from the nonconditioned ones $(P>0.05$ in the two cases). This effect was smaller in P18 pups, whose performance fell halfway between those of conditioned and nonconditioned ones $(P=0.0019$ and $P<0.0001$, respectively). At this age the amnesia generated by AN after the cue was only partial.

These results are in accordance with data obtained in the adult showing that new protein synthesis is required for memory consolidation and for reconsolidation of a reactivated memory. However, in the P18 pups, the amnesic effect of AN is weaker after either acquisition or reactivation. Thus, the question that arises is whether this decline of retroactive amnesia results from an abrupt or a progressive decrease of the time frame of protein synthesis-dependent memory formation.

\section{Temporal gradients of AN efficacy at different ages}

To address this question, these experiments were designed to determine the temporal gradients of efficacy of AN on aversion memory at different ages, P3, P10, and P18, after either acquisition or reactivation. In both conditions, six groups of conditioned pups received AN i.p. at different delays: 0, $15 \mathrm{~min}, 30$ $\min , 1 \mathrm{~h}, 6 \mathrm{~h}$, and $24 \mathrm{~h}$.

\section{Consolidation}

When AN was given immediately after conditioning at the three ages, the resulting amnesia was similar to that observed in the previous experiment, confirming the reliability of these data.

The efficacy of AN decreased when its time of delivery was delayed, thus demonstrating a temporally graded effect (one-way ANOVA, delays $0-24 \mathrm{~h}$; at P3: $F_{(5,42)}=29.72, P<0.0001$; at P10: $F_{(5,49)}=26.68, P<0.0001$; at P18: $\left.F_{(5,40)}=9.03, P<0.0001\right)$. The temporal gradients of efficacy shortened as the pups developed (see Fig. 2A). At P3 with a delay of one hour AN efficacy decreased; this group was different from both the conditioned nonAN-treated $(P<0.0001)$ and the conditioned receiving AN immediately $(P=0.006)$. AN had no effect with 6 - and 24 -h delays; 
A Consolidation


Figure 2. Time-dependent effect of anisomycin after acquisition or reactivation. At the different ages $(\mathrm{P3}, \mathrm{P} 10, \mathrm{P} 18)$ AN was given at different delays after training $(A)$ or reactivation $(B)$, either immediately (AN 0) or $15 \mathrm{~min}, 30 \mathrm{~min}, 1 \mathrm{~h}, 6 \mathrm{~h}$, or $24 \mathrm{~h}$. (A) CS-US, pups of groups conditioned at P3, P10, or P18 $(n=7,9,8)$; CS---US+AN, unconditioned pups receiving $\mathrm{AN}$ at P3, P10, or P18 $(n=8,9,8)$; CSUS+AN, conditioned pups receiving $\mathrm{AN}$ at different delays at the different ages: $\mathrm{P} 3(n=8,8,9,7,8$, 8), P10 $(n=10,10,9,9,9,8), \mathrm{P} 18(n=7,8,8,8,8,7)$. (B) CS-US/R, pups conditioned at P3, P10, P18 and reactivated $(n=8,9,8) ; \mathrm{CS}-\mathrm{US} / \mathrm{R}+\mathrm{AN}$, conditioned and reactivated pups receiving AN at different delays, P3 $(n=8,8,8,7,8,8), \mathrm{P} 10(n=9,9,9,9,9,8), \mathrm{P} 18(n=9,8,8,9,9,8)$; CS-US/NR+AN, pups conditioned but nonreactivated receiving $\mathrm{AN}(n=9,9,9) ; \mathrm{CS}---\mathrm{US} / \mathrm{R}+\mathrm{AN}$, pups nonconditioned, cued, and receiving $\mathrm{AN}(n=8,9,8)$. Error bars indicate $\mathrm{SE}$. ${ }^{* * *} P<0.001 ;{ }^{* *} P<0.01$. Note that the temporal gradient of efficacy of AN shortens with age after either acquisition or reactivation.

these groups did not differ from the conditioned non-AN-treated one.

At P10, AN efficacy decreased with delays of 15 and 30 min; both these groups differed from the conditioned one receiving AN immediately after training $(P<0.0001$ in each case). The amnesia was even less marked with 1-h delay; in this group, the aversion was stronger than in the 30 -min delay $(P=0.01)$, but weaker than in the 6 -h one $(P=0.01)$.

At P18, the decrease in the AN efficacy was faster than in the younger pups. AN administered at time 0 had a weak efficacy; the conditioned pups receiving AN were different from both the conditioned non-AN-treated and nonconditioned ones $(P<0.0001$ in both cases). From time $15 \mathrm{~min}$ to $24 \mathrm{~h}$ every group expressed an aversion identical to that of the conditioned non-ANtreated one $(P>0.05)$

\section{Reconsolidation}

The results confirmed the amnesic effect when AN was given immediately after reactivation and also its lack of effect when it was not paired with a reminder cue.

As observed in the previous experiments, the delay of delivery determined the efficacy of AN treatment (one-way ANOVA, delays $0-24 \mathrm{~h}$; at P3: $F_{(5,41)}=118, P<0.0001 ;$ at $\mathrm{P} 10$ : $F_{(5,47)}=214, P<0.0001$; at $\mathrm{P} 18$ : $\left.F_{(5,45)}=30.5, P<0.0001\right)$. The impairment in aversion memory progressively decreased as the interval between cueing and AN injection increased (see Fig. 2B).

Overall, we observed a decrease in time during which AN was effective after reactivation as a function of age. At P3, the group receiving AN $1 \mathrm{~h}$ after reactivation had a lower retention than the conditioned and cued non-AN-treated $(P<0.0001)$. At P10, only the group with AN at time 0 differed from the conditioned and cued non-AN-treated $(P<0.0001)$, but the amnesia in this group was complete, since it did not differ from the nonconditioned group. At $\mathrm{P} 18$, the group receiving $\mathrm{AN}$ at time 0 showed a partial amnesia, since it differed from both the conditioned and nonconditioned $(P<0.0001$ in each case).

These experiments reveal similar development-related reduction of temporal gradients after acquisition and reactivation. Thus, it seems that the temporal dynamics of consolidation and reconsolidation dependent on protein synthesis shorten with age.

\section{Effect of intraventricular injection of $\mathrm{AN}$ at the different ages}

The decrease of AN effectiveness in the pre-weaning period could also result from a decrease of AN penetration into the brain tissue. It is known that the blood brain barrier (BBB) matures at about 2 wk after birth (Utsumi et al. 2000); thus, it could result in a longer time required for AN to reach cerebral targets.

From the temporal gradients of efficacy, it appeared that the one-hour delay was a critical moment: AN was still effective at P3, its effectiveness decreased at P10, and it disappeared at P18. If the evolution of the gradients depends on BBB permeability, then intraventricular (i.c.v.) injection, which bypasses this barrier, should allow AN to keep a constant efficacy at the 1-h interval regardless of the age of the animals.

At the three ages we used two groups of conditioned animals: half received an i.c.v. injection of AN $1 \mathrm{~h}$ after conditioning at a volume adjusted for age (see Materials and Methods), the 
others received a saline injection. At this 1-h interval we observed an evolution of the amnesic effect of AN i.c.v., as a function of age, similar to AN i.p. (see Fig. 3A). At P3, there was a clear retrograde amnesia $(P<0.0001)$; the amnesia was less marked at P10 but still present $(P=0.016)$ and it disappeared at P18. Thus, the putative obstacle created by BBB reinforcement cannot explain the loss of the amnesic effect of AN during development.

\section{Effect of AN on protein synthesis at the different ages}

To verify that the decrease in the amnesic effect of AN with age was not due to a decrease in its ability to inhibit protein synthesis, we measured protein synthesis inhibition in the brain induced by the same dose of AN i.p. injected ( $42 \mathrm{mg} / \mathrm{kg}$ ) at P3, P10, and P18 as in the previous experiments. Protein synthesis inhibition was assayed by comparing the ratio of amino acid radiolabeled ${ }^{35} \mathrm{~S}$-methionine incorporated in two groups, one $\mathrm{AN}$ - and the other saline-injected. Results are presented in Figure 3B. The rates of inhibition at the three ages were of the same order, $\sim 90 \%$ (95\%, 93\%, and 90\%, respectively), which was congruent with the inhibition observed with a dose of $\mathrm{AN}$ of $30 \mathrm{mg} / \mathrm{kg}$ that induced $>90 \%$ inhibition at a delay of $1 \mathrm{~h}$ (Davis et al. 1980).



protein synthesis inhibition

B



Figure 3. (A) Comparison of the effects of anisomycin one hour after acquisition at P3, P10, P18 when delivered either in intraperitoneal or intraventricular injections. CS-US, conditioned non-AN-treated pups (i.c.v., $n=12,10,8)$; CS-US+AN, conditioned pups which received AN (i.c.v., $n=13,10,9)$. Intraperitoneal results are extracted from Experiment 2. Error bars indicate SE. ${ }^{* * *} P<0.001$; ${ }^{* *} P<0.01$; ${ }^{*} P<0.05$. In both conditions the amnesic effect of AN decreases similarly from P3 to P18. (B) Measures of protein synthesis inhibition by comparison of incorporation of ${ }^{35} \mathrm{~S}$-methionine in groups of pups receiving saline versus groups receiving anisomycin. Measures of inhibition were done one hour after injection. At the three ages, the protein synthesis inhibition induced by $\mathrm{AN}$ is $\geq 90 \%$.
That reinforces the results of intracranial injections; a decrease in efficacy of AN cannot account for the decrease in its amnesic effect.

\section{Temporal dynamics of consolidation and reconsolidation at the same age}

The comparison between the temporal dynamics of consolidation and reconsolidation in the second experiment suggested the latter one could be shorter, and that was particularly detectable at P10. At this age AN was still effective $1 \mathrm{~h}$ after acquisition but had no effect with 15-min delay after retrieval. However, it must be noted that reconsolidation occurred $2 \mathrm{~d}$ after consolidation and the aging of animals could also be the cause of this difference. To test these two possibilities, we measured the duration of efficacy of AN when consolidation occurred at P12 instead of P10. The results showed (Fig. 4) that the temporal gradient of efficacy was halfway between these obtained on P12 for reconsolidation and on P10 for consolidation. Like for reconsolidation, AN had no effect when delivered on 30-min and 1-h time points. But like for consolidation at P10, AN had a partial amnesic effect when delivered $15 \mathrm{~min}$ after acquisition. This group differed from both the conditioned non-AN-treated one and the conditioned one which received AN immediately $(P=0.004$ and $P=0.0001$, respectively). Thus, it seems that $2 \mathrm{~d}$ of development cannot totally account for the decrease of the temporal gradient, as P12 consolidation appears still longer than reconsolidation.

\section{Effect of a high dose of $\mathrm{AN}$ on post-weaning rats}

Considering the very short period during which the AN was effective at the end of nursing, we tested the effect of AN at a dose of $210 \mathrm{mg} / \mathrm{kg}$, the highest dose generally used in the adult (Davis et al. 1980; Tronel et al. 2005), in post-weaning rats at the age of P35. The animals were autonomous, so they were submitted to a conventional paradigm of conditioned taste aversion where they were allowed to drink aromatized water (CS) from pipettes and 30 min later poisoned (US) by $\mathrm{LiCl}$ injection. As the delay of $\mathrm{AN}$ efficacy post-trial could be too brief, we also delivered AN half an hour pretrial, in consolidation or reconsolidation conditions.

The results are presented in Figure 5. When AN was injected immediately after training in the conditioned group (CSUS+AN), a partial impairment of the aversion was observed; these rats were different from those of the conditioned non-AN-treated group $(P=0.017)$ and from those of the unconditioned control groups $(P<0.0005$ in both cases). When AN was administered 30 min before training (AN+CS-US) the impairment of aversion was more obvious, these rats were not significantly different from those of the nonconditioned groups $(P>0.05)$, and they tended to express less aversion than those of the conditioned group injected after training $(P=0.1)$.

Immediately after reactivation $\mathrm{AN}$ at $210 \mathrm{mg} / \mathrm{kg}$ had no effect. The conditioned rats receiving AN (CS-US/R+AN) were not significantly different from the conditioned non-AN-treated ones $(P>0.05)$, but an effect of AN was found using the same dose administered $30 \mathrm{~min}$ before the reactivation session. Rats in this conditioned group (CS-US/AN+R) showed partial impairment of the aversion; these rats were different from those of the other conditioned groups and those of the nonconditioned group $(P<0.0001$ in all cases).

These results show that at P35 even a high dose of AN delivered immediately after acquisition or reactivation induces a weak amnesia and that dose is more efficient when administered earlier.

\section{Discussion}

The main result of these experiments is that the temporal gradient of efficacy of anisomycin to induce amnesia decreases after 


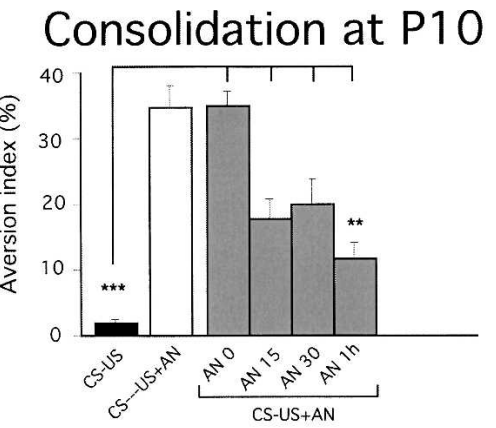

\section{Consolidation at P12}



Reconsolidation at P12

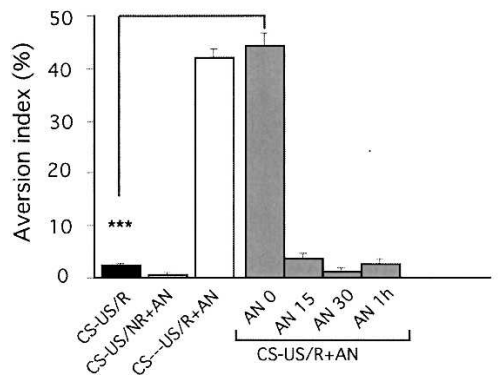

Figure 4. Temporal dynamics of consolidation and reconsolidation at the same age. Consolidation at P12 shows the post-acquisition effect of AN when training was on P12; CS-US, conditioned pups $(n=10)$; CS--US+AN, unconditioned pups $(n=10)$; CS-US+AN, conditioned pups receiving AN at different delays, either $0,15,30 \mathrm{~min}$ or $1 \mathrm{~h}$ after acquisition $(n=10,11,10,10)$. Reconsolidation at $\mathrm{P} 12$ shows the post-reactivation effect of AN when training was on P10 and reactivation on P12. Consolidation at $\mathrm{P} 10$ and reconsolidation at $\mathrm{P} 12$ are extracts from Experiment 2. Error bars indicate SE. ${ }^{* * *} P<0.001 ;{ }^{* *} P<0.01$. At $\mathrm{P} 12$, AN postacquisition had an amnesic effect at time 15 min but was ineffective at this delay after reactivation. Thus, at the same age reconsolidation appears shorter than consolidation.

both acquisition and reactivation as a function of animal growth (Fig. 2). This phenomenon allows different interpretations along three lines: (1) It may reflect a decrease of effectiveness of AN to inhibit protein synthesis; (2) the conditions of learning may evolve with age so that the amnesic agent loses its effectiveness; and (3) the processing of memory may become less timedemanding with age.

First, it can be proposed that AN loses its efficacy to induce amnesia during a prolonged period of time because it takes more time to reach its cellular target as the subjects grow. Another possibility is that the catabolism of $\mathrm{AN}$ accelerates with age so that inhibition does not last for enough time in the oldest pups. In either case, it will not have sufficient early protein inhibition after learning or reactivation. Two arguments rule out this interpretation: (1) This cannot be due to the reinforcement of the blood brain barrier since intraventricular injection at $1 \mathrm{~h}$ after learning produces the same amnesic effects at the three ages as when given intraperitoneally (Fig. 3A); thus, skirting the blood brain barrier does not extend the time during which AN is effective. (2) The effectiveness of AN measured $1 \mathrm{~h}$ after i.p. injection is maintained at the three ages (Fig. 3B). In either case the protein synthesis inhibitions are $\geq 90 \%$, above the level required for inducing amnesia (80\%-90\%) (Davis et al. 1981; Davis and Squire 1984; Milekic and Alberini 2002; Dudai 2004; Luft et al. 2004). It must be noted that at this one-hour delay AN-delivered i.p. is still effective to induce amnesia in $\mathrm{P} 3$, the protein synthesisdependent consolidation is not finished, AN has no effect in P18, and consolidation and reconsolidation appear completed at this delay.

Moreover, we have tested the effect of a high dose of AN $(210 \mathrm{mg} / \mathrm{kg}$ ) which inhibits $>97 \%$ of protein synthesis (Milekic and Alberini 2002) on conditioned taste aversion memory in autonomous rats (P35) with AN injection before (30 min) or immediately after acquisition or reactivation. In these conditions the induced amnesia was more marked when AN was injected 30 min before the trial; after acquisition the amnesia was weak and nil when given after reactivation (Fig. 5). These results at P35 with a high dose of AN confirm the effect observed at P18 with a low dose. For all these reasons, it appears that the decrease of the time bound amnesic effect of AN cannot be explained simply by a decrease of effectiveness of AN on protein synthesis with age.

Second, age variations in the time course of AN effectiveness may result from differences with age in the establishment of learned aversion and thus in the level of conditioning. Arguing against this is the fact that there is no obvious change in the rate of conditioned response with age; at the three ages all conditioned saline-treated rats exhibit a strong aversion. But it could be argued that similar rates of conditioning may result from a



Figure 5. Effect of anisomycin at a dose of $210 \mathrm{mg} / \mathrm{kg}$ delivered after or before either acquisition $(A)$ or reactivation $(B)$ in $\mathrm{P} 35$ rats. The rats were conditioned on P35 to taste aversion by drinking aromatized water (CS) and then poisoning (US) by $\mathrm{LiCl}$ injection. As in the previous experiments, retention test for consolidation took place $3 \mathrm{~d}$ after training. For reactivation the cueing episode took place $2 \mathrm{~d}$ after training and retention test was $2 \mathrm{~d}$ later. The used groups were the same as in Experiment 1; the only differences are that one group received AN 30 min before training (AN+CS-US, $n=9$ ) and one before cueing (CS-US/AN+R, $n=8)$. ( $A$ ) CSUS, conditioned $(n=11)$; CS-US+AN, conditioned receiving AN immediately after training $(n=11)$; CS---US, nonconditioned $(n=11)$; CS--US+AN, nonconditioned receiving AN $(n=11)$. (B) CS-US/R, conditioned and reactivated $(n=10) ; C S-U S / R+A N$, conditioned and reactivated receiving AN immediately after cueing $(n=8) ; C S---U S / R+A N$, nonconditioned and cued receiving AN $(n=10) ; C S-U S / N R+A N$, conditioned but nonreactivated receiving $\mathrm{AN}(n=10)$. Error bars indicate SE. ${ }^{* * *} P<0.001 ;{ }^{*} P<0.05$. At $\mathrm{P} 35$, a high dose of AN has only a partial amnesic effect and this effect is more obvious when it is given before acquisition or reactivation. In post-trial administration, note the similarity with the effects of AN at P18 obtained in Experiments 1 and 2 though here the dose of $\mathrm{AN}$ was fivefold higher. 
ceiling effect, the aversion being too strong at either age to reveal any differences in conditioning. These differences could be due to variation of the impact of deprivation on the pups. For instance the stress resulting from dam separation may have hormonal and neural consequences changing during growth. That could induce differences in the internal context of the pups at the time of learning, thereby causing differences in the sensitivity to the amnesic agent. In the same way, a one-night fast may induce different declines in energetic reserves of the pups at P3 and P18. One can think that P3 pups are more dependent on suckling than the P18 ones, so that the younger have a greater decrease in glucose availability that may impair memorization (Gold 2005). But, on the other hand, it could induce a greater hunger in the P3 pups and so a stronger motivation for the milk, which can facilitate learning and make it more resistant to amnesia.

The salience of CS and US used for conditioning may vary with age. In the P3 pups the contrast between taking milk from the surrogate nipple and from the mother may be less obvious than in the P18, even if the milk is aromatized to be distinct from the mother's one. The reduced salience of the CS in that case may lessen conditioning and render the memory trace more sensitive to the amnesic agent (McGaugh 1966; Flood et al. 1972). That would be in accordance with the complete amnesia observed when AN is given after acquisition at P3 and P10, and not at P18 (Figs. 1, 2). However, to assume that the memory is weaker in the P3 pups does not fit well the results obtained after reactivation. Indeed it has been shown that reactivation of a weak trace leads to extinction; consequently, an amnesic treatment acting on this new learning protects the original memory (Eisenberg et al. 2003). That is not the case here, since cueing induces a new period of sensitivity to amnesia of the original memory, thus indicating that memory formed at P3 is a strong one.

Concerning the US (discomfort), its salience may also vary with age, or its reinforcing value could change during the nursing period and so modify the level of conditioning. Nevertheless, there is a strong similarity in the evolution of temporal gradients after both acquisition and reactivation at the different ages, even though the US is missing for reactivation.

That leads to a third line of interpretation, which considers that the time frame of protein synthesis-dependent memory trace stabilization changes as the animal develops. This proposal agrees with conditioned taste aversion data in the adult where the amnesic effect of protein synthesis inhibition is always obtained with treatment delivered before the end of training (Tucker and Oei 1982; Rosenblum et al. 1993; Houpt and Berlin 1999; Berman and Dudai 2001). These data, taken together with the results of the present experiments, suggest that the trainingto-treatment time window for impairing long-term memory of conditioned aversion is very short in the adult.

By suggesting that consolidation and reconsolidation grow shorter with age, we do not mean that the temporal gradient of efficacy of AN measures directly the duration of these processes. It is well known that the temporal gradients vary considerably with the nature of the amnesic agent used (McGaugh 1966; Gibbs and Ng 1978; Rosenzweig et al. 1993). However, by using the same dose of AN in the same task, we can have an indication of the duration of this crucial stage for long-term memory formation. With respect to this stage, the durations of consolidation and reconsolidation evolve in parallel during development; in the adult, similarities and differences between them are still being explored (Dudai 2004; Alberini 2005; Tronel et al. 2005; Davis and Laroche 2006; Sara and Hars 2006; Tronson and Taylor 2007). The parallelism observed here during postnatal development suggests that both involve some common processes.

The decrease in time necessary for both consolidation and reconsolidation may reflect two different phenomena: (1) The processing of memory is similar at the different ages, as it is realized faster in the older rats, then the process accelerates. For instance, if the need for new proteins for stabilization of memory is constant from P3 to P18, then this requirement is more rapidly completed at P18. (2) The processing of memory decreases with development, so the operations need less time to be accomplished at a constant speed. For instance if the need in new proteins declines with age, the pool required for stabilization is produced in a shorter time. Either by an acceleration or a reduction of memory processing the observed result is the same, i.e., a decrease of the duration during which the memory remains sensitive to disruption by AN.

About the effect of AN, our basic assumption is that it impairs memorization by blocking protein synthesis, but it is known that AN, like many drugs, has effects on other biochemical and physiological targets. It has even been proposed that some of these side effects could be the actual causes of its amnestic effect. This issue has been previously debated (see Davis and Squire 1984) but not completely resolved and has currently been reexamined in the light of new data. For instance Gold's group shows that AN triggers an overshoot of norepinephrine (NE) and that an excess in NE around the time of training may impair memory (Canal et al. 2007). On the other hand, Rudy and colleagues propose that AN may induce apoptosis and so damage the neural population supporting the memory (Rudy et al. 2006). AN may also induce a "superinduction" of immediate-early genes, which could impair cellular mechanisms of memory formation (Radulovic and Tronson 2008). This discussion is not closed and there are still a majority of recent papers interpreting the amnestic effect of AN by its blockage of protein synthesis. Hernandez and Abel (2008) argue that recent, more targeted approaches, at the molecular and genetic levels, fit the hypothesis that protein synthesis plays an important role in memory formation. In this line of reasoning we have shown in the same paradigm that MAPK/ERK pathway is necessary for consolidation and reconsolidation of memory in pups (Languille et al. 2007).

It is not impossible that the amnesic effect of protein synthesis inhibitors could be multifaceted, but, regardless of the outcome of this debate, the main fact here is that memory escapes more rapidly from lability with development. Thus, a question arises about the causes of the decrease in time required for memory processing. Brain maturation continues during weeks after birth, neurogenesis and neuronal migrations have not ended, and synaptogenesis and myelination processes are very active (Bayer et al. 1993; Rice and Barone 2000). Considering this, some possibilities among many may be offered for changes in learning ability or memory processing.

Shortening of time required for memory stabilization may result from a preparation of the neural network in which the memory trace is embedded. If the establishment of the memory trace requires modification of the network, these modifications may be easier to implement because of the enrichment of neural connectivity during growth. At the time of new learning, there would be an easier integration of the new information into a well-established underlying network. The fact that at P12 the time window of AN sensitivity was shorter after retrieval than after learning argues in favor of this view; reconsolidation of a memory seems to benefit from the reinforcement previously implemented during its consolidation. On the other hand, in older rats AN never induced a total amnesia like in P3 and P10 pups, even with a high dose of AN given before training. A part of memory escapes from the impairment, which suggests that the memory becomes less dependent on de novo protein synthesis with age.

Arousal may have a facilitative effect on acquisition and also 
on memorization. Treatments that increase the level of brain activation such as psycho-stimulant drugs or brain stimulation improve memory when administered during consolidation (McGaugh 1966; Bloch 1970) or reconsolidation periods (Devietti et al. 1977). Enhanced brain activation along with growth may facilitate memory processes and so shorten the time for memory stabilization. That could result from maturation of modulatory systems such as cholinergic and noradrenergic systems (Harley 2004; Moriceau and Sullivan 2004; Field et al. 2007; Mellott et al. 2007), which are both involved in arousal and memory. It could be noted that a release of catecholamines with AN (Canal et al. 2007), given developmental differences in sensitivity to these modulators, may also explain why AN affects pups of different ages differently. For instance, lack of autoinhibition in locus coeruleus could render the pups more sensitive to noradrenaline (Nakamura and Sakaguchi 1990; Moriceau and Sullivan 2004).

Change in memory processes may also result from change in the neural circuits involved. Sullivan and colleagues, using odor-shock conditioning, which induces an approach response before P10 and avoidance afterward, have clearly demonstrated that the paradoxical preference in the younger pups reflects the inability to engage the amygdala at the time of learning (Sullivan 2001). They confirm this key role of the amygdala in pup learning in a paradigm of odor aversion where an odor is paired with lithium chloride injection. They show that conditioning induces an odor aversion in P7, P12, and P23 pups and that the aversion is independent of amygdala in P7 and P12 pups, but implicates it in P23 pups. The neural circuit supporting the same learned behavior may be different in the pup and the weanling rat (Shionoya et al. 2006). Such a change in the substrates of learning may involve differences in memory processing and modify its duration.

Regardless of the mechanisms involved in the memory processes growing shorter, this phenomenon could be one of the factors responsible for the cognitive improvement seen in the course of growth. For instance, the longer period of lability of memory makes it more fragile in the young and should be a factor in infantile amnesia (Campbell and Spear 1972). Of course, in normal life, pups are not given anisomycin, but an early memory should stay more sensitive to retroactive interference, which can impair its later retrieval. By making a new memory less vulnerable, the saving of time may improve the capacity to store new items and to update memory.

Interestingly, a symmetrical phenomenon could exist during aging. Davis and colleagues measured the amnesic effect of AN in mice of three age groups. They find a prolonged gradient of retrograde amnesia in the older mice (14-15 mo) as compared to young (2-3 mo) or intermediate (6-7 mo), and they demonstrated that this prolongation could not be accounted for by differential inhibition of brain protein synthesis (Davis et al. 1981). That suggests the memory processes grow shorter during growth and get longer in old age. Similarities in infants and old rats have been also underlined in the retrieval of memories after forgetting (Spear 1976). Similarities in the dynamics of memory at the beginning and the end of life does not necessary imply they are attributable to common mechanisms. Nevertheless, modifications in cognitive abilities occurring during growth and senescence could be better understood by taking into account changes in the temporal dynamics of memory processes.

\section{Materials and Methods}

\section{Subjects}

Male and female Wistar rat pups (originating from Wistar parents; Iffa-Credo) were used as subjects. On the day of birth (P0), litters were culled to six pups. The litters were kept with their respective mothers until the age of $22 \mathrm{~d}$. The mothers and their litters were housed in standard maternity cages with ad libitum access to food and water, and maintained in a temperaturecontrolled colony room on a 12-h light/dark cycle. All experimental procedures were performed in conformity with national (JO 887-848) and European (86/609/EEC) legislation.

\section{Anisomycin administration}

\section{Intraperitoneal injection (i.p.)}

On the days of conditioning or of reactivation, anisomycin (AN) (Sigma), dissolved in $0.9 \%$ saline and adjusted to $\mathrm{pH} 7.2$ with $1 \mathrm{~N}$ $\mathrm{HCl}$, was injected i.p. (42 mg/kg or $210 \mathrm{mg} / \mathrm{kg}$ in the last experiment) after training or reactivation. The dose of $42 \mathrm{mg} / \mathrm{kg}$ was previously shown to be effective in producing a total amnesia in P3 pup (Gruest et al. 2004b) and the dose of $210 \mathrm{mg} / \mathrm{kg}$ is the upper one commonly used in adult rodent (Davis et al. 1980; Tronel et al. 2005). Control rats were injected with $0.9 \%$ saline.

\section{Intraventricular injection (i.c.v.)}

One hour after conditioning, animals were briefly anesthetized with inhalation of isoflurane vapor, and AN $(25 \mu \mathrm{g} / \mu \mathrm{L}, \sim 0.3 \%$ brain weight: $2 \mu \mathrm{L}$ for P3, $2.5 \mu \mathrm{L}$ for P10, and $3.5 \mu \mathrm{L}$ for P18) was injected in the left ventricle $(0.5 \mathrm{~mm}$ posterior to bregma, $1 \mathrm{~mm}$ lateral to the sagittal suture; depth, $3 \mathrm{~mm}$ ). Control rats received a saline injection in the same conditions.

\section{Training procedure}

We used a paradigm of conditioned taste/odor aversion in pups and P35 rats. In this paradigm, the conditioned stimulus (CS; peach-aromatized drink) was given for $10 \mathrm{~min}$ and paired $30 \mathrm{~min}$ later with an injection of $0.15 \mathrm{M} \mathrm{LiCl}$ (2\% body weight, i.p.; Sigma) that causes an immediate malaise (unconditioned stimulus, US). In pups the CS (peach-aromatized milk; Régilait) was given via a surrogate nipple and in P35 rats it was via $12-\mathrm{mL}$ pipettes (peach-aromatized water). In pups and P35, control rats were submitted to an unpaired condition with a long delay $(\sim 8 \mathrm{~h})$ between CS and US.

Pups were isolated from the dam $\sim 11 \mathrm{~h}$ before training and were exposed in the morning to the surrogate nipple as described in previous articles (Petrov et al. 1997; Gruest et al. 2004b). All pups were returned to their dam at the same time $\sim 3 \mathrm{~h}$ after the beginning of conditioning, regardless of treatment delays (see Fig. 6).

P35 rats were water-deprived $36 \mathrm{~h}$ before training. During this deprivation, free access to water was permitted for $15 \mathrm{~min}$ in the home cages at the end of the afternoon. On the day of training, pipettes filled with the CS were presented to the rats in an experimental room.

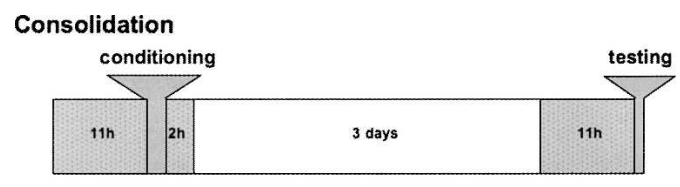

\section{Reconsolidation}

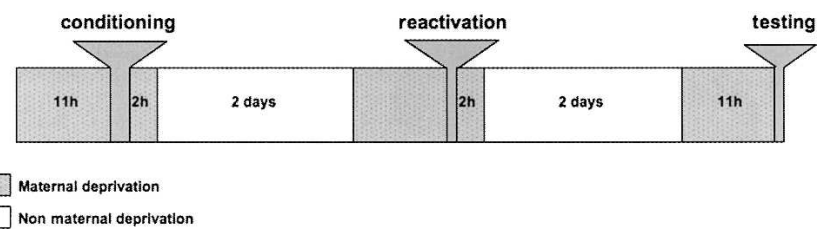

Figure 6. Pup's planning in consolidation and reconsolidation protocols. 


\section{Reactivation treatments}

The reactivation session occurred $2 \mathrm{~d}$ after acquisition. In pups, reactivation consisted of intraoral contact with the surrogate nipple filled with aromatized milk. To equalize reactivation between pups, the nipple was imposed on the pups by putting it into their mouth for a 5-min period. Before cueing, all pups were isolated from the dams as for conditioning.

In P35 rats, reactivation consisted of a 5-min licking session in the experimental room, with pipettes containing peacharomatized water. Immediately after this session and in order to equalize the treatments between rats, $2 \mathrm{~mL}$ of the aromatized water was delivered in the mouth via a syringe.

\section{Testing}

Three days after conditioning (consolidation) or $2 \mathrm{~d}$ after reactivation (reconsolidation), the CS was presented in the morning for a 10-min session, as described for conditioning.

For pups, this was conducted $\sim 11 \mathrm{~h}$ following isolation from the dam. During testing, as for conditioning, the attractiveness of aromatized milk was assessed by the time spent attached to the nipple and the weight gain of pups during the suckling session. The two measures were generally well correlated, and we used the time of attachment as it appeared a more discriminative measure and showed better expression of the active response of the pups. This higher level of sensitivity of attachment has been showed before by Nizhnikov et al. (2002). The total time of attachment to the nipple was measured on-line by two experimenters who were blind to the pretreatment of the pups.

In P35 rats, this session was conducted following water deprivation, as for conditioning. All rats were exposed to pipettes filled with the aromatized water for $10 \mathrm{~min}$. At the end of the session, fluid intake was measured with a precision of $0.1 \mathrm{~mL}$.

\section{Measurement of protein synthesis inhibition}

The level of protein synthesis inhibition after i.p. injection of anisomycin was measured via incorporation of ${ }^{35} \mathrm{~S}$-labeled methionine (NEN) into newly synthesized proteins. Fifteen minutes after $\mathrm{AN}$ or $\mathrm{NaCl} 0.9 \%$, animals ( $n=8$ /group) were anesthetized with isoflurane, and $1 \mu \mathrm{L}$ of ${ }^{35} \mathrm{~S}$-methionine $(10 \mathrm{mCi} / \mathrm{mL}$, containing $10 \mathrm{mM}$ 2-mercaptoethanol, a stabilizer) was injected in the left ventricle. One hour after methionine injection, animals were decapitated, and the forebrain was quickly dissected on icecold PBS ( $\mathrm{pH} \mathrm{7.0)}$. We took two tissue samples $\left(40 \mathrm{~mm}^{3}\right)$ per animal and they were analyzed independently.

Protein synthesis inhibition was measured using methods described previously (Luft et al. 2004). Briefly, the tissue sample was homogenized, centrifugated, and the supernatant was collected. Radioactivity of the protein pellet (trichloroacetic acid precipitable cellular protein fraction) and that of the supernatant were counted. For each animal, a pellet-to-supernatant index, $i$, was computed as the ratio of pellet scintillation counts to supernatant counts. The percentage of protein synthesis inhibition was then calculated using the following formula: $\left(1-\right.$ mean $\left[i_{\mathrm{AN}}\right] /$ mean $\left.\left[i_{\mathrm{NaCl}}\right]\right) \times 100$.

\section{Data analysis}

To ensure independence of the data, only one pup from a litter was assigned to a given condition. A taste aversion index was calculated as the relative time spent attached to the nipple: (time during testing/total time during conditioning and testing) $\times 100$. This was chosen to limit the potential interindividual variability in the oral grasping response and to take into account the conditioning session. Thus, the more the pups refused the flavored milk nipple (aversion), the lower the score was.

In P35 rats the aversion scores for individual rats were expressed as the relative fluid intake: (fluid intake during testing/ total fluid intake during conditioning and testing) $\times 100$. As for pups, this score was thus defined to minimize the effect of individual variability in fluid consumption, and the lower the score, the stronger the aversion.

ANOVA and $t$-tests were used for statistical analyses. Data from both males and females were combined because ANOVA confirmed that there was no sex difference in any measures reported here.

\section{Acknowledgments}

We thank Susan Sara for critical comments on this manuscript; Mauricette Collado-Hilly and Jean-Claude Sulpice for teaching the measure of radiolabeled protein; and Pascale Veyrac, Nathalie Samson, and Gérard Dutrieux for their technical assistance.

\section{References}

Alberini, C.M. 2005. Mechanisms of memory stabilization: Are consolidation and reconsolidation similar or distinct processes? Trends Neurosci. 28: 51-56.

Bayer, S.A., Altman, J., Russo, R.J., and Zhang, X. 1993. Times tables of neurogenesis in the human brain based on experimentally determined patterns in the rat. Neurotoxicology 14: 83-144.

Berman, D.E. and Dudai, Y. 2001. Memory extinction, learning anew, and learning the new: Dissociations in the molecular machinery of learning in cortex. Science 291: 2417-2419.

Bloch, V. 1970. Facts and hypotheses concerning memory consolidation processes. Brain Res. 24: 561-575.

Campbell, B.A. and Spear, N.E. 1972. Ontogeny of memory. Psychol. Rev. 79: $215-236$.

Canal, C.E., Chang, Q., and Gold, P.E. 2007. Amnesia produced by altered release of neurotransmitters after intraamygdala injections of a protein synthesis inhibitor. Proc. Natl. Acad. Sci. 104: 12500-12505.

Cheslock, S.J., Varlinskaya, E.I., Petrov, E.S., and Spear, N.E. 2000. Rapid and robust olfactory conditioning with milk before suckling experience: Promotion of nipple attachment in the newborn rat. Behav. Neurosci. 114: 484-495.

Davis, S. and Laroche, S. 2006. Mitogen-activated protein kinase/extracellular regulated kinase signalling and memory stabilization: A review. Genes Brain Behav. 5: 61-72.

Davis, H.P. and Squire, L.R. 1984. Protein synthesis and memory: A review. Psychol. Bull. 96: 518-559.

Davis, H.P., Rosenzweig, M.R., Bennett, E.L., and Squire, L.R. 1980. Inhibition of cerebral protein synthesis: Dissociation of nonspecific effects and amnesic effects. Behav. Neural Biol. 28: 99-104.

Davis, H.P., Rosenzweig, M.R., Kinkade, P.T., and Bennett, E.L. 1981. Effects of anisomycin on retention of the passive-avoidance habit as a function of age. Exp. Aging Res. 7: 33-44.

Devietti, T.L., Conger, G.L., and Kirkpatrick, B.R. 1977. Comparison of the enhancement gradients of retention obtained with stimulation of the mesencephalic reticular formation after training or memory reactivation. Physiol. Behav. 19: 549-554.

Dudai, Y. 2004. The neurobiology of consolidations, or, how stable is the engram? Annu. Rev. Psychol. 55: 51-86.

Dudai, Y. and Eisenberg, M. 2004. Rites of passage of the engram: Reconsolidation and the lingering consolidation hypothesis. Neuron 44: 93-100.

Eisenberg, M., Kobilo, T., Berman, D.E., and Dudai, Y. 2003. Stability of retrieved memory: Inverse correlation with trace dominance. Science 301: 1102-1104.

Field, S.E., Rickard, N., Toukhsati, S., and Gibbs, M. 2007. Maternal hen calls modulate memory formation in the day-old chick: The role of noradrenaline. Neurobiol. Learn. Mem. 88: 321-330.

Flood, J.F., Bennett, E.L., Rosenzweig, M.R., and Orme, A.E. 1972. Influence of training strength on amnesia induced by pretraining injections of cycloheximide. Physiol. Behav. 9: 589-600.

Garcia, J., Ervin, F.R., and Koelling, R.A. 1966. Learning with prolonged delay of reinforcement. Psychon. Sci. 5: 121-122.

Gibbs, M. and Ng, K.T. 1978. Memory formation for an appetitive visual discrimination task in young chicks. Pharmacol. Biochem. Behav. 8: $271-276$.

Gold, P.E. 2005. Glucose and age-related changes in memory. Neurobiol. Aging 26: 60-64.

Gruest, N., Richer, P., and Hars, B. 2004a. Emergence of long-term memory for conditioned aversion in the rat fetus. Dev. Psychobiol. 44: 189-198.

Gruest, N., Richer, P., and Hars, B. 2004b. Memory consolidation and reconsolidation in the rat pup require protein synthesis. J. Neurosci. 24: 10488-10492.

Harley, C.W. 2004. Norepinephrine and dopamine as learning signals. Neural Plast. 11: 191-204. 
Hernandez, P.J. and Abel, T. 2008. The role of protein synthesis in memory consolidation: Progress amid decades of debate. Neurobiol. Learn. Mem. 89: 293-311.

Houpt, T.A. and Berlin, R. 1999. Rapid, labile, and protein synthesis-independent short-term memory in conditioned taste aversion. Learn. Mem. 6: 37-46.

Kehoe, P. and Blass, E.M. 1986. Conditioned aversions and their memories in 5-day-old rats during suckling. J. Exp. Psychol. Anim. Behav. Process. 12: 40-47.

Languille, S., Alcacer, C., Richer, P., and Hars, B. 2007. Inhibition of MAPK pathway blocks consolidation and reconsolidation of memory in the pup. In 8e Colloque de la Société des neurosciences, Abstract K.32. Montpellier, France.

Luft, A.R., Buitrago, M.M., Ringer, T., Dichgans, J., and Schulz, J.B. 2004. Motor skill learning depends on protein synthesis in motor cortex after training. J. Neurosci. 24: 6515-6520.

McGaugh, J.L. 1966. Time dependent processes in memory storage. Science 153: 1351-1358.

McGaugh, J.L. 2000. Memory-A century of consolidation. Science 287: 248-251.

Mellott, T.J., Follettie, M.T., Diesl, V., Hill, A.A., Lopez-Coviella, I., and Blusztajn, J.K. 2007. Prenatal choline availability modulates hippocampal and cerebral cortical gene expression. FASEB J. 21: $1311-1323$.

Milekic, M.H. and Alberini, C.M. 2002. Temporally graded requirement for protein synthesis following memory reactivation. Neuron 36: $521-525$.

Moriceau, S. and Sullivan, R.M. 2004. Unique neural circuitry for neonatal olfactory learning. J. Neurosci. 24: 1182-1189.

Nader, K. 2003. Memory traces unbound. Trends Neurosci. 26: 65-72.

Nader, K., Schafe, G.E., and Le Doux, J.E. 2000. Fear memories require protein synthesis in the amygdala for reconsolidation after retrieval. Nature 406: 722-726.

Nakamura, S. and Sakaguchi, T. 1990. Development and plasticity of the locus coeruleus: A review of recent physiological and pharmacological experimentation. Prog. Neurobiol. 34: 505-526.

Nizhnikov, M.E., Petrov, E.S., Varlinskaya, E.I., and Spear, N.E. 2002. Newborn rats' first suckling experience: Taste differentiation and suckling plasticity. Physiol. Behav. 76: 181-198.

Petrov, E.S., Varlinskaya, E.I., and Smotherman, W.P. 1997. The newborn rat ingests fluids through a surrogate nipple: A new technique for the study of early suckling behavior. Physiol. Behav. 62: 1155-1158.

Radulovic, J. and Tronson, N.C. 2008. Protein synthesis inhibitors, gene superinduction and memory: Too little or too much protein? Neurobiol. Learn. Mem. 89: 212-218.
Rice, D. and Barone Jr., S. 2000. Critical periods of vulnerability for the developing nervous system: Evidence from humans and animal models. Environ. Health Perspect. 108: 511-533.

Rosenblum, K., Meiri, N., and Dudai, Y. 1993. Taste memory: The role of protein synthesis in gustatory cortex. Behav. Neural Biol. 59: $49-56$.

Rosenzweig, M.R., Bennett, E.L., Colombo, P.J., Lee, D.W., and Serrano, P.A. 1993. Short-term, intermediate-term, and long-term memories. Behav. Brain Res. 57: 193-198.

Rudy, J.W., Biedenkapp, J.C., Moineau, J., and Bolding, K. 2006. Anisomycin and the reconsolidation hypothesis. Learn. Mem. 13: $1-3$.

Sara, S.J. 2000. Retrieval and reconsolidation: Toward a neurobiology of remembering. Learn. Mem. 7: 73-84.

Sara, S.J. and Hars, B. 2006. In memory of consolidation. Learn. Mem. 5: 515-521.

Shionoya, K., Moriceau, S., Lunday, L., Miner, C., Roth, T.L., and Sullivan, R.M. 2006. Development switch in neural circuitry underlying odor-malaise learning. Learn. Mem. 13: 801-808.

Smotherman, W.P. 2002. Classical conditioning in the rat fetus: Temporal characteristics and behavioral correlates of the conditioned response. Dev. Psychobiol. 40: 116-130.

Smotherman, W., Stickrod, G., and Kimble, D. 1982. In utero taste/odor aversion in the rat. Physiol. Behav. 28: 5-7.

Spear, N.E. 1976. Ontogenetic factors in the retrieval of memories. Act. Nerv. Super. (Praha) 18: 302-311.

Sullivan, R.M. 2001. Unique characteristics of neonatal classical conditioning: The role of the amygdala and locus coeruleus. Integr. Physiol. Behav. Sci. 36: 293-307.

Tronel, S., Milekic, M.H., and Alberini, C.M. 2005. Linking new information to a reactivated memory requires consolidation and not reconsolidation mechanisms. PLoS Biol. 3: 1630-1638.

Tronson, N.C. and Taylor, J.R. 2007. Molecular mechanisms of memory reconsolidation. Nat. Rev. Neurosci. 8: 262-275.

Tucker, A.R. and Oei, T.P. 1982. Protein synthesis inhibition and amnesia for saccharin aversion memory in rats after intra-cisternal administration of cycloheximide. Physiol. Behav. 28: 1025-1028.

Utsumi, H., Chiba, H., Kamimura, Y., Osanai, M., Igarashi, Y., Tobioka, H., Mori, M., and Sawada, N. 2000. Expression of GFR $\alpha-1$, receptor for GDNF, in rat brain capillary during postnatal development of the BBB. Am. J. Physiol. Cell Physiol. 279: C361-C368.

Received January 25, 2008; accepted in revised form April 7, 2008. 


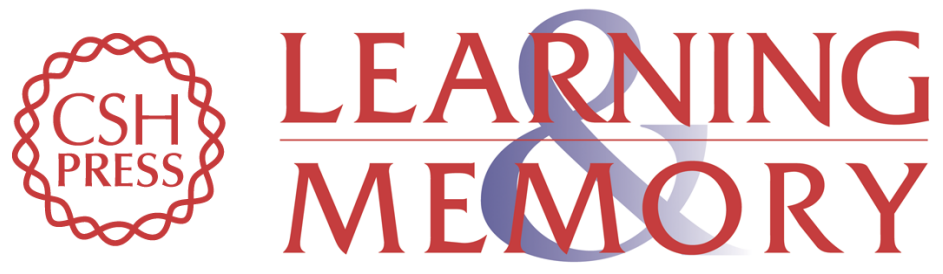

\section{The temporal dynamics of consolidation and reconsolidation decrease during postnatal development}

Solène Languille, Nadège Gruest, Paullette Richer, et al.

Learn. Mem. 2008, 15:

Access the most recent version at doi:10.1101//m.933208

References This article cites 53 articles, 12 of which can be accessed free at: http://learnmem.cshlp.org/content/15/6/434.full.html\#ref-list-1

License

Email Alerting

Receive free email alerts when new articles cite this article - sign up in the box at the Service top right corner of the article or click here. 